\title{
Contents in brief
}

List of figures xiv

List of tables $\quad \mathrm{xv}$

List of contributors $\quad$ xvi

Introduction 1

\section{Part I Theoretical building blocks}

1 Strategic alliances as agents of competitive change 13 Kathryn Rudie Harrigan

2 Inter-partner learning in strategic alliances 20 Yves Doz

3 Alliances: a distinct strategic tool for reconfiguring resources and businesses

Laurence Capron and Will Mitchell

4 Alliances and markets for technology

Alfonso Gambardella and Claudio Panico

5 Real option considerations in devising a collaborative strategy

Tailan Chi and Anju Seth

6 Collaboration in strategic alliances: cooperation and coordination

Tobias Kretschmer and Bart S Vanneste

\section{Part II Partner selection and alliance investment decisions}

$7 \quad$ Alliance partner selection

Dan Li, Jingyu Li and Michael A Hitt

8 Strategic alliance as a mode of international market entry 
9 When collaborative strategy turns into acquisition: distinguishing and explaining partner acquisition versus joint venture buyout

Miranda Stienstra and Xavier Martin

10 Alliances and exogenous shocks Navid Asgari and Kulwant Singh

\section{Part III Contractual foundations of alliances}

11 Contractual design of alliances Kyle J Mayer and Zhe (Adele) Xing

12 Property rights theory and the governance of strategic alliances Daniel W Elfenbein

13 Global knowledge acquisition through alliances: optimizing contracts and task complexity Farok J Contractor and Jeongho Choi

\section{Part IV Relational and behavioral aspects of alliances}

14 The relational view revisited Jeff Dyer, Harbir Singh and William Hesterly

15 The process of cooperation in strategic alliances Birgul Arslan and Africa Ariño

16 The social context of B2B exchanges: trust and relational governance

Laura Poppo and Truc Nguyen

17 Behavioral alliance strategy

Thomas Mellewigt, Sarah Maria Bruhs and Arne Keller

18 Culture in alliance research Franz Wohlgezogen

19 A stakeholder-based view of strategic alliances 168 Kerstin Neumann and Maurizio Zollo

\section{Part V Alliance networks and portfolios}

20 The network perspective of alliances: taking stock and looking ahead

Ravi Madhavan and John Prescott 
21 The architecture and dynamics of global networks Maxim Sytch

22 Managing the configuration and evolution of alliance portfolios Werner H Hoffmann and Ferry Habasche

23 Exploration and exploitation through alliances Dovev Lavie

\section{Part VI Novel collaborative relationships}

24 Business ecosystems

Robert P Bremner, Kathleen M Eisenhardt and Douglas P Hannah

25 Public-private collaboration: a review and avenues for further research

Ilze Kivleniece, Sandro Cabral, Sergio Lazzarini and Bertrand V Quélin

26 Multi-party technology alliances

Caren Butter and John Hagedoorn

\section{Part VII Consequences of inter-organizational collaboration}

27 Alliance performance

Miguel Rivera-Santos and Pierre Dussauge

28 You are the company you keep: the relationship between an organization's alliance activity and its status Ithai Stern

29 Addressing endogeneity issues in alliance research Octavio J Martinez, Joanne E Oxley and Brian S Silverman

30 Alliance or partnering capability of a firm: antecedents, constituents and performance implications

Prashant Kale and Harbir Singh

References

Index 